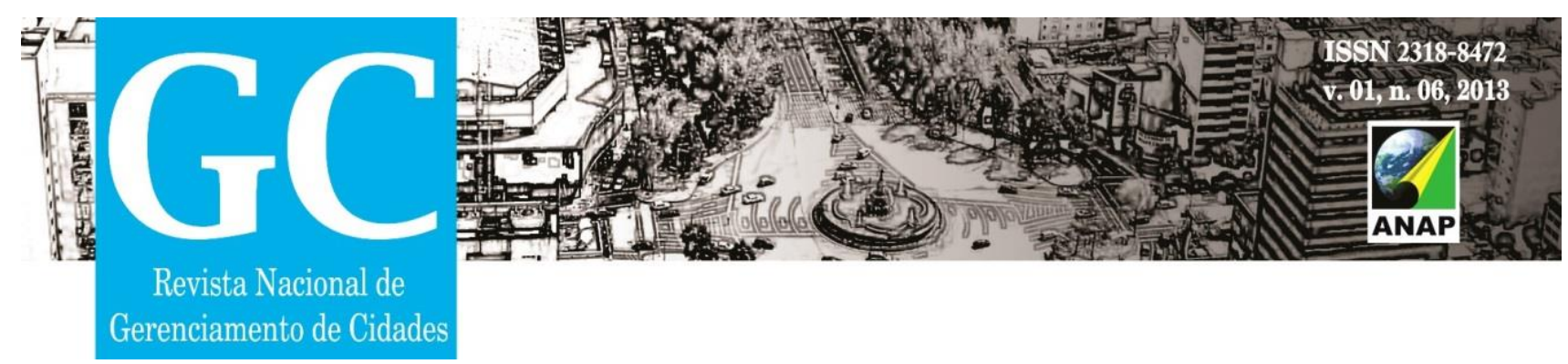

\title{
COLAPSO DE SOLO DESENCADEADO PELA ELEVAÇÃO DO NÍVEL D’ÁGUA
}

Roger Augusto Rodrigues ${ }^{1}$

\section{Orencio Monje Vilar ${ }^{2}$}

RESUMO: Este artigo apresenta um caso histórico de colapso dos solos que ocorreu durante e após o enchimento do reservatório da UHE Três Irmãos na região noroeste do Estado de São Paulo. A construção desta barragem e o subseqüente enchimento do reservatório elevaram significativamente o lençol freático, causando uma série de problemas. Trabalhos de campo e de laboratório foram realizados para determinar o potencial de risco associado às edificações existentes no local. A elevação do lençol freático foi monitorada especialmente para o estudo de recalques de edificações. São apresentados os aspectos principais do processo de colapso deflagrado na região e as conseqüências advindas de sua ocorrência, bem como, a importância da colapsibilidade na elaboração de projetos de engenharia, visando minimizar impactos em áreas urbanas.

Palavras- Chave: Colapso do solo. Lençol freático. caso histórico.

\section{INTRODUÇÃO}

\footnotetext{
${ }^{1}$ Doutor em Geotecnia, Escola de Engenharia de São Carlos da Universidade de São Paulo (EESC/USP). Professor Assistente Doutor do Departamento de Engenharia Civil e Ambiental da Universidade Estadual Paulista "Júlio de Mesquita Filho" (UNESP/Bauru). E-mail: roger_ar@feb.unesp.br

${ }^{2}$ Doutor em Geotecnia, Escola de Engenharia de São Carlos da Universidade de São Paulo (EESC/USP). Professor Titular do Departamento de Geotecnia da Escola de Engenharia de São Carlos da Universidade de São Paulo. E-mail: orencio@sc.usp.br
} 


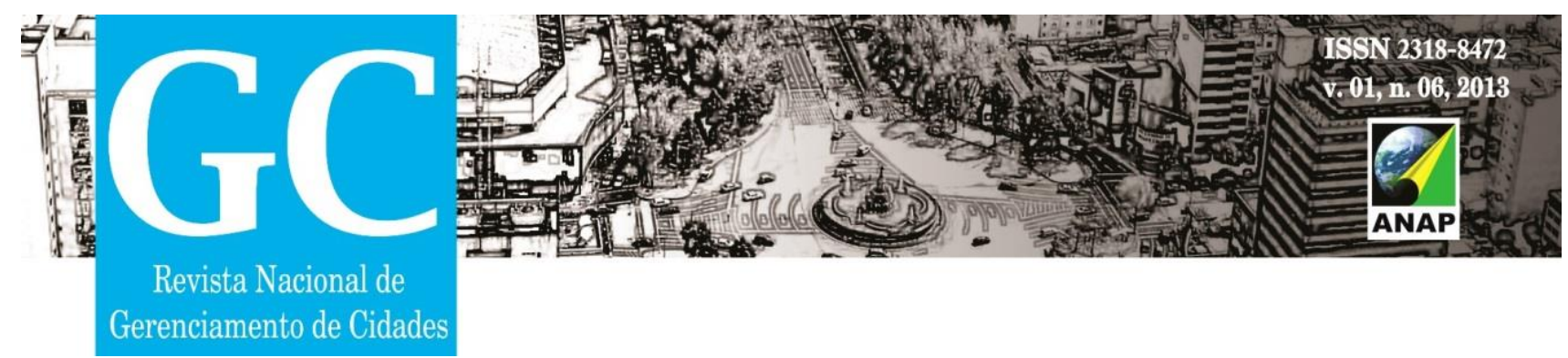

O colapso do solo pode ser conceituado como uma deformação provocada pelo umedecimento de um solo sem que haja variação de sobrecargas. O umedecimento atinge os mecanismos de suporte do solo, originando um desequilíbrio estrutural. Tal problema pode ser responsável por recalques (deslocamentos verticais) em obras civis, ocasionando desde pequenos danos, como o aparecimento de pequenas trincas em paredes, a danos de maior magnitude, como ruína parcial ou total de paredes, pisos e instalações hidráulicas.

Mesmo considerando que as perdas decorrentes de tal processo tenham um caráter eminentemente econômico, sua quantificação, caso efetuada, proporcionaria resultados expressivos, dada a grande disseminação do problema.

Os solos colapsíveis apresentam algumas características que os predispõem ao fenômeno, tais como: uma estrutura porosa caracterizada por um alto índice de vazios, baixos valores de umidade com graus de saturação na maioria das vezes inferiores a $60 \%$ e uma estrutura com porosidade acima de $40 \%$.

Em zonas urbanas, o colapso dos solos normalmente está associado a chuvas intensas ou de longa duração e a rompimentos de tubulações enterradas de água e de esgoto doméstico. No entanto, há casos particulares onde o colapso pode ser previsto antecipadamente e, portanto, acompanhado. Um exemplo disto ocorreu com o solo da cidade de Pereira Barreto que se mostrou suscetível ao colapso durante o enchimento do reservatório da Usina Hidrelétrica de Três Irmãos, instalada no baixo curso do Rio Tietê.

As características hidrogeológicas da região, assim como as cotas topográficas dos terrenos ocasionaram grandes elevações no lençol freático na área urbana da cidade, culminando em grandes recalques em várias edificações construídas na área de maior influência do reservatório.

Já que os recalques eram esperados, algumas edificações foram monitoradas antes e durante a subida do lençol freático. Medidores de nível d'água, marcos de recalque, inclinômetros, dentre outros instrumentos, foram instalados para esta finalidade. Ensaios de 


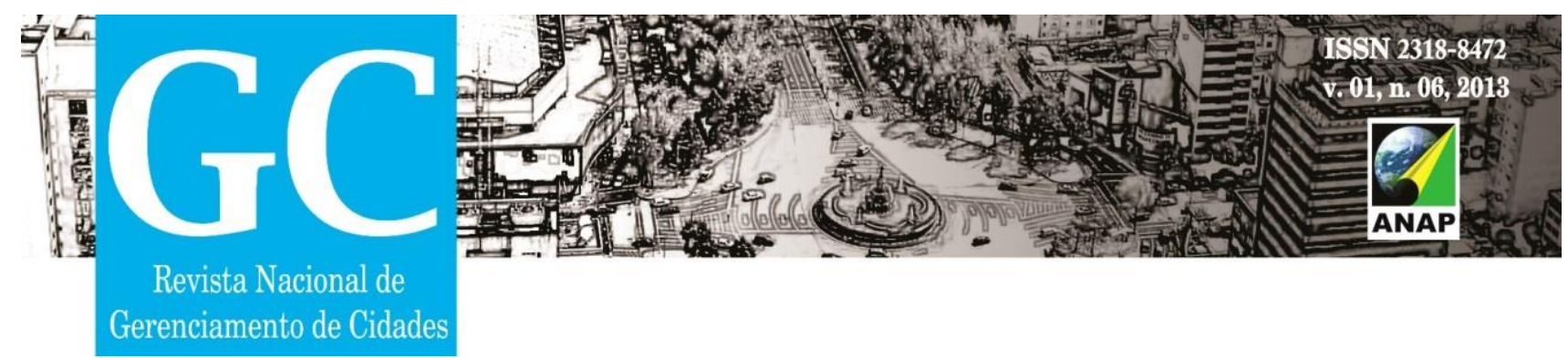

laboratório e de campo também foram realizados na região a fim de auxiliar futuras análises e previsões dos impactos causados pela subida do nível d'água.

\section{SOLOS COLAPSÍVEIS}

Alguns solos, ao se aumentar o conteúdo de água em seus vazios ou ao serem carregados e posteriormente umedecidos experimentam uma redução de volume manifestada por uma brusca variação índice de vazios sem o aumento das cargas aplicadas. Têm-se atribuído esse fenômeno a um colapso da estrutura do solo, de onde a designação de solo colapsível (VILAR et al., 1981).

Determinadas regiões do globo terrestre apresentam condições para o desenvolvimento de solos colapsíveis. Seja pela lixiviação de finos dos horizontes superficiais nas regiões onde se alternam estações de relativa seca e de precipitações intensas, o que origina solos de elevada porosidade, como ocorre no Centro-Sul do Brasil, ou pelos solos com deficiência de umidade que se desenvolvem em regiões áridas e semiáridas (VILAR et al., 1981).

O colapso representa um problema corriqueiro e a disseminação dos solos colapsíveis fez com que o estudo do fenômeno tenha se tornado necessário, principalmente em regiões onde os solos colapsíveis servem como fundação de obras de grande porte, como os canais de irrigação e as grandes barragens da Região Centro-Sul do Brasil.

Em todo o mundo registros indicam que muitos solos colapsíveis são procedentes de depósitos residuais, coluvionares, eólicos, aluviais e, ainda, de aterros compactados. (DUDLEY, 1970; NUÑES, 1975; CLEMENCE \& FINBAR, 1981; VILAR et al., 1981; VILAR \& GAIOTO, 1994).

$\mathrm{Na}$ Figura 1 são demonstrados os locais em que os solos colapsíveis são estudados no Brasil. 

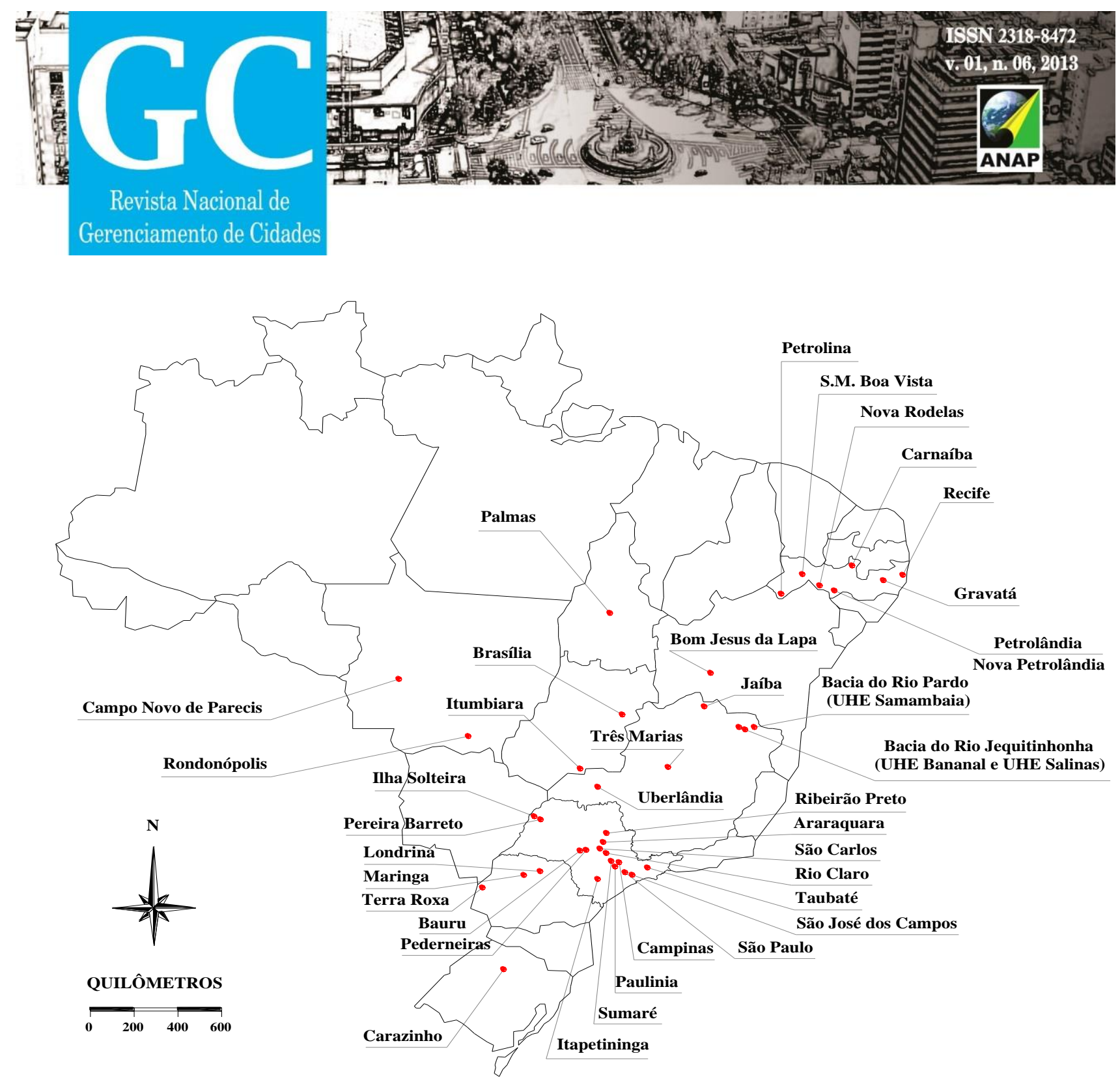

Figura 1. Solos colapsíveis estudados no Brasil.

\section{PROCESSO DE ELEVAÇÃO INDUZIDA DO LENÇOL FREÁTICO}

A construção de uma usina hidrelétrica causa mais interferências no meio físico do que qualquer outra obra civil de grande porte, as quais regem as reações do meio ambiente procurando se adaptar às novas condições impostas (ALBUQUERQUE FILHO, 2002; SANTOS, 2002). Das interferências, a elevação induzida do lençol freático adjacente a reservatórios hidrelétricos é uma das mais importantes. A Figura 2 ilustra o esquema da evolução do processo de elevação induzida no lençol freático. 

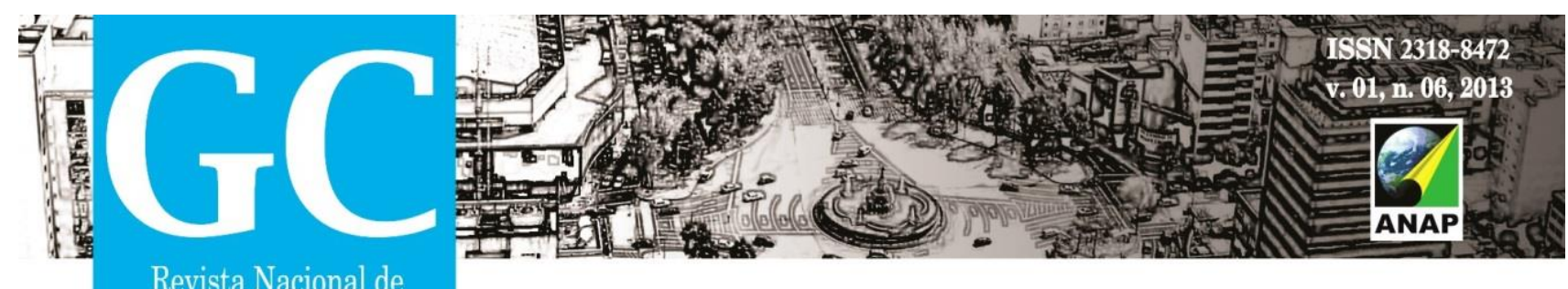

Gerenciamento de Cidades

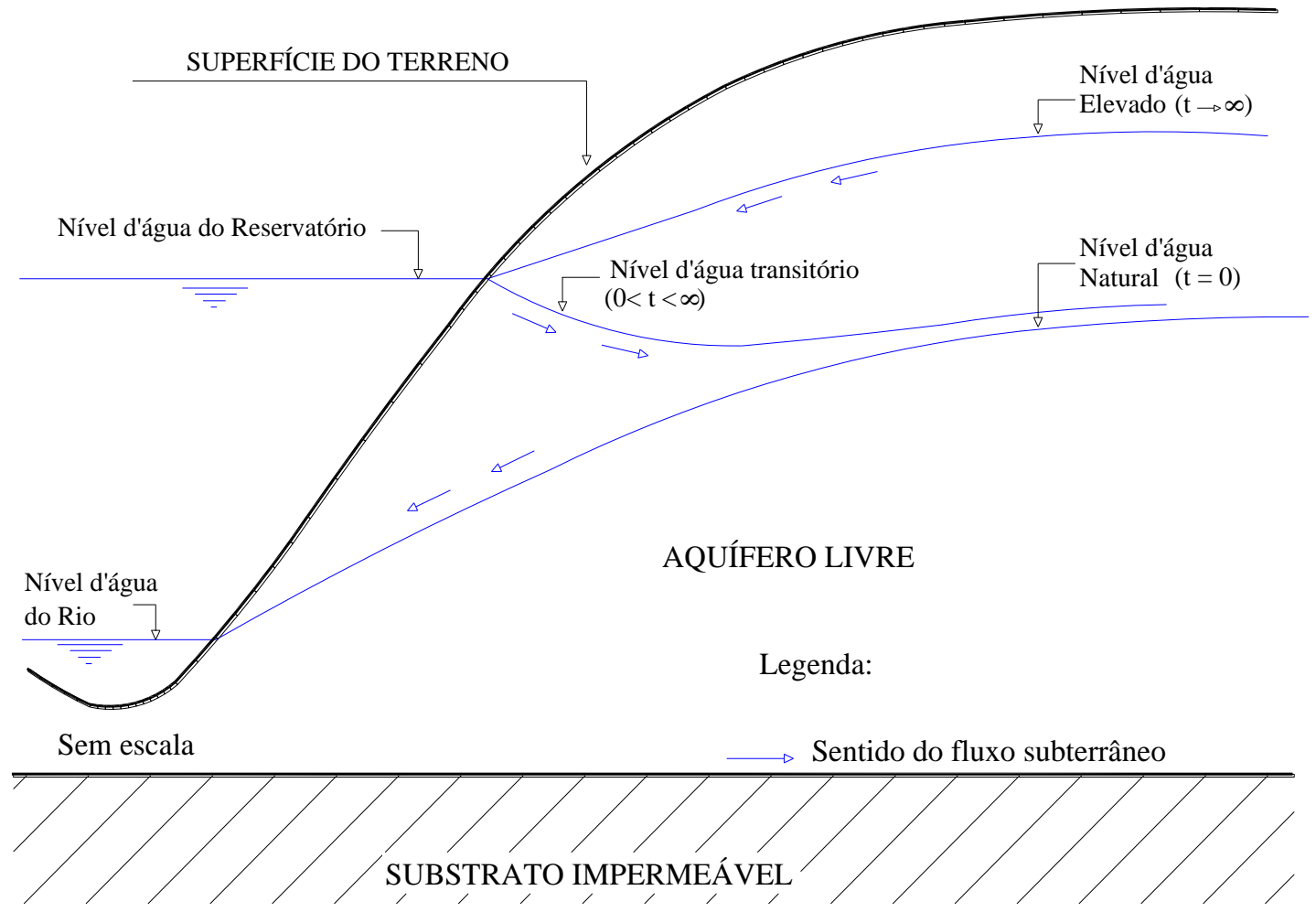

Figura. 2. Modelo esquemático da evolução do processo de elevações induzidas no lençol freático nas bordas de reservatórios (SANTOS, 2002).

Esse impacto resulta do fato de que, antes do represamento da água do reservatório da barragem, o rio possuía nível mais baixo que as vizinhanças, funcionando como coletor da descarga dos aqüíferos adjacentes. Quando ocorre o barramento, as águas do rio elevam-se de tal modo que, temporariamente, o rio passa a alimentar o aqüífero livre adjacente. Esta condição impõe um processo de elevação continuada do lençol freático, até que o sistema seja equilibrado novamente, isto é, que o sentido do fluxo da água subterrânea volte a se desenvolver no sentido do rio para o reservatório.

A magnitude e a distribuição da elevação induzida no lençol freático no domínio espaço-tempo são condicionadas por aspectos hidrogeológicos, hidrológicos, climatológicos, 

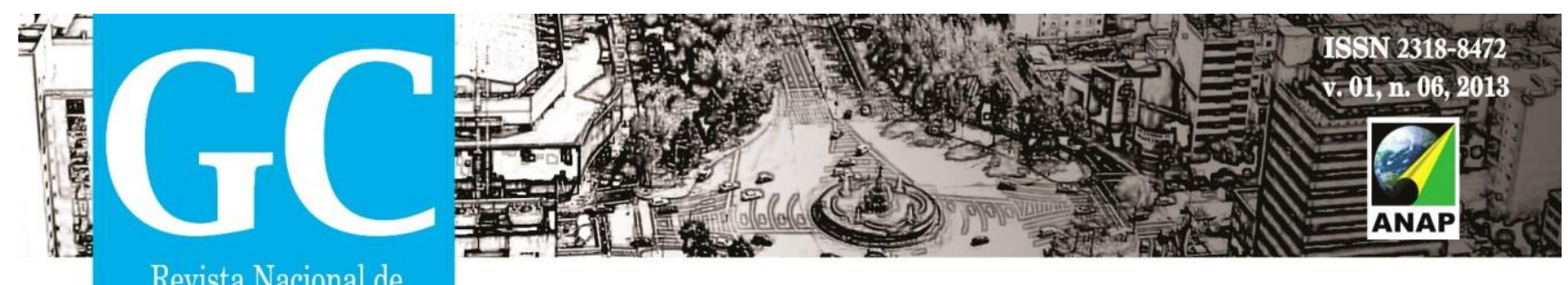

Gerenciamento de Cidades

geológicos, geomorfológicos e pedológicos, aliados às características construtivas e operacionais do reservatório hidrelétrico. A nova situação estabelecida poderá se traduzir em um resultado positivo ou negativo, em relação àquela anteriormente existente. Isso dependerá de qual enfoque está sendo considerado para o elemento água, seja ele como recurso hídrico, seja com agente ativo nos processos naturais do meio físico, ou ocasionando reflexos nos usos e ocupações do solo, tanto os existentes como aqueles que venham, porventura, a se estabelecer nas bordas do reservatório (ALBUQUERQUE FILHO, 2002).

\section{CASO HISTÓRICO DE PEREIRA BARRETO-SP}

Desde os primeiros estudos realizados na década de 80 , a cidade de Pereira Barreto mostrou-se suscetível à elevação do lençol freático, devido ao represamento do lago da UHE de Três Irmãos. As características do solo da região trouxeram consigo a necessidade de trabalhos investigatórios que conduzissem a resultados adequados para previsões dos impactos e que auxiliassem a tomada de ações preventivas e corretivas por parte da Companhia Energética de São Paulo (CESP), concessionária responsável pelo empreendimento.

No ano de 1985 iniciaram-se os estudos da avaliação do processo de elevação do lençol freático sobre áreas de uso e ocupação de destaque do solo como na área urbana de Pereira Barreto, situada à cerca de $20 \mathrm{~km}$ a montante da barragem de Três Irmãos, no baixo curso do Rio Tietê. Os possíveis problemas advindos da elevação do lençol freático nesse local foram levantados, inicialmente, pelo Instituto de Pesquisas Tecnológicas (IPT) com base em estudo regional, compreendendo a bacia de contribuição do reservatório. O IPT iniciou estudos de detalhamento dos impactos na cidade, consubstanciados pela fase de levantamento do acervo de dados disponíveis (ALBUQUERQUE FILHO, 2002). 

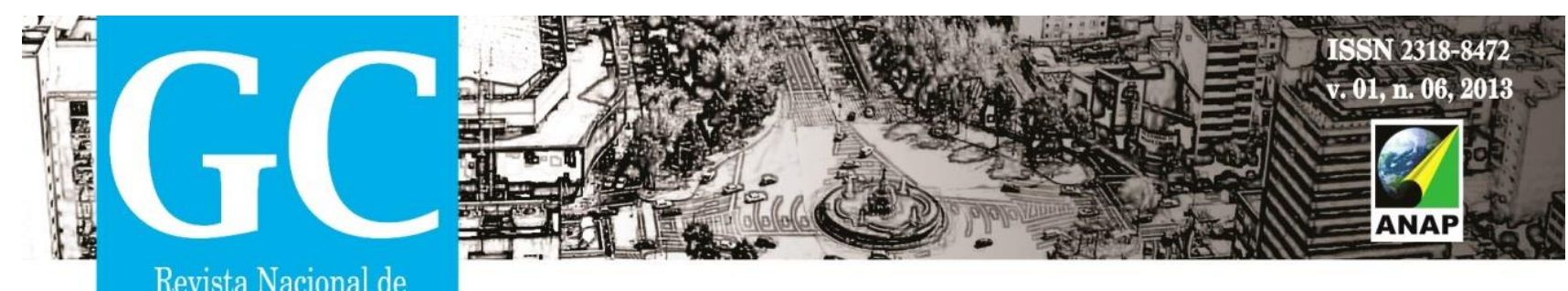

Revista Nacional de

Gerenciamento de Cidades

Posteriormente, foram realizados estudos hidrogeológicos na região com a instalação de piezômetros, abertura de poços, execução de ensaios de bombeamento e permeabilidade; estudos geológicos com o levantamento de mapas geológicos e topográficos; geofísicos com sondagens elétricas verticais; e estudos geotécnicos com a instrumentação para acompanhamento de recalques de edificações, além da execução de outros ensaios de campo e de laboratório.

Desde os estudos preliminares, buscou-se identificar a influência do enchimento do reservatório através de zoneamento. A resposta final desta identificação resultou em um mapa de potencial de influência do enchimento do reservatório (Figura 3).

Este mapa é definido como um instrumento cartográfico que demonstra a distribuição das novas zonas de profundidade finais máximas do lençol freático, alteando como decorrência do completo enchimento do reservatório (ALBUQUERQUE FILHO, 2002).

A obtenção do mapa final possibilitou aos responsáveis pela construção da usina hidrelétrica a delimitação de áreas ou zonas com as futuras profundidades do lençol freático. Destas, a área denominada Zona A mostrou-se a mais crítica, já que a previsão apontava uma posição final do nível d'água entre 0 e 5 metros de profundidade. 

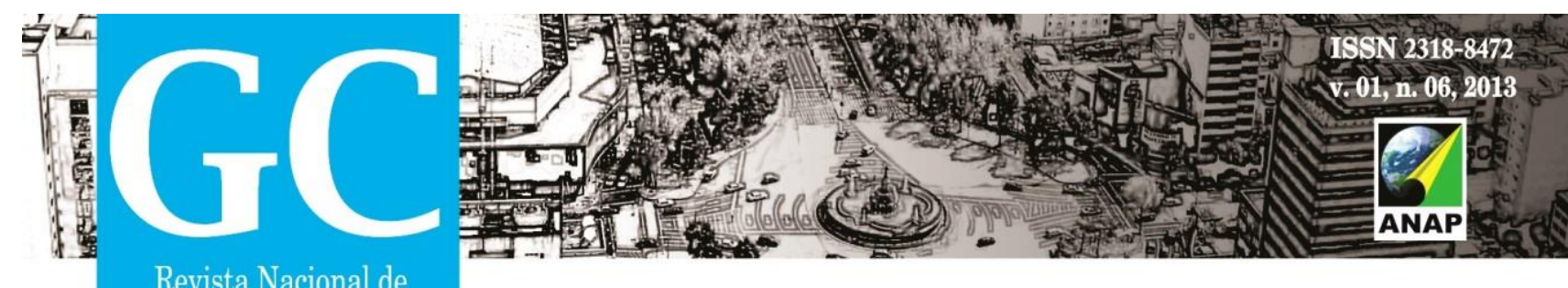

Gerenciamento de Cidades

locais de investigação geotécnica

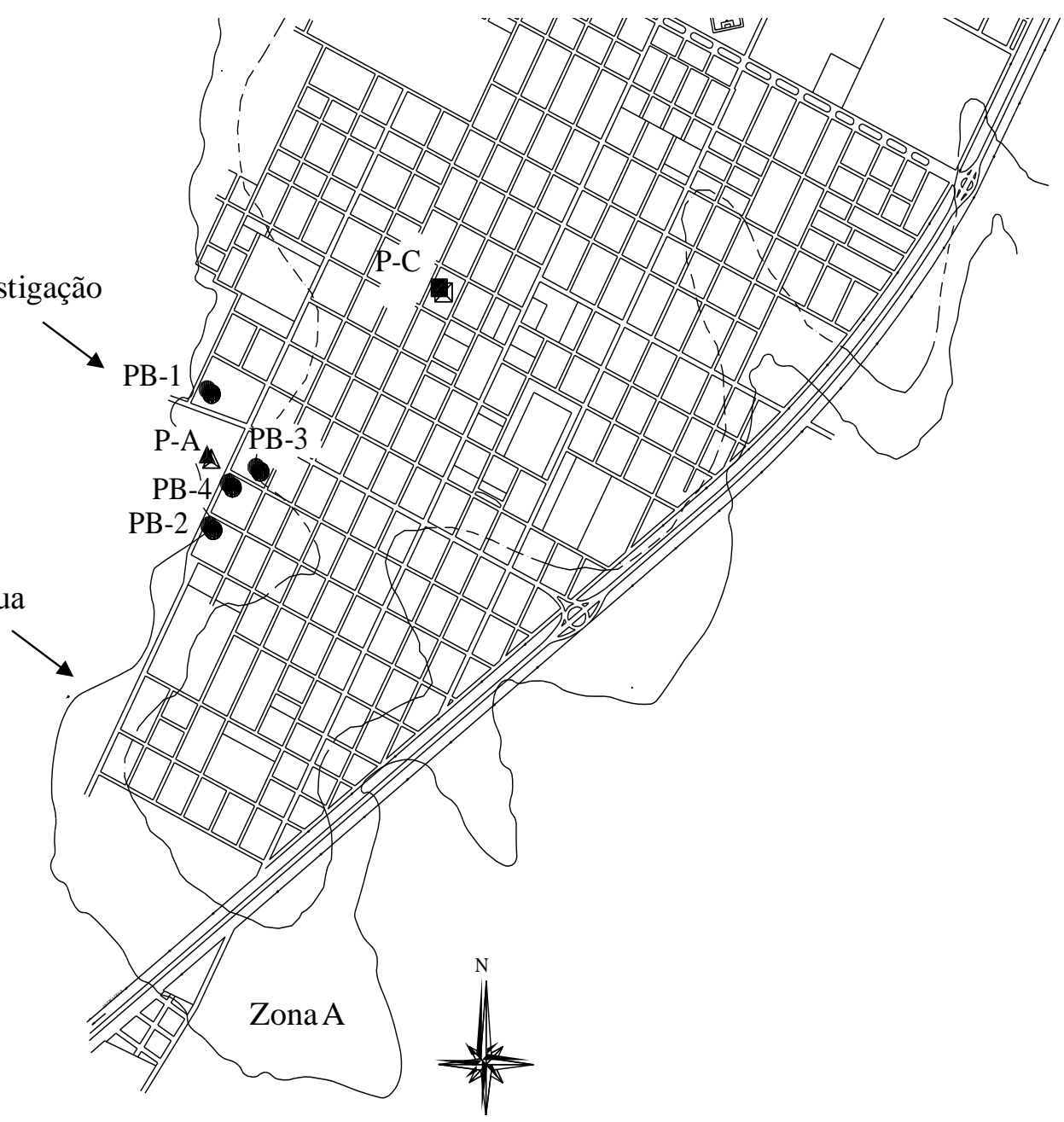

Figura 3. Mapa de potencial de influência do enchimento do reservatório com identificação da Zona $A$ (profundidade do nível d'água entre 0 e 5 m) (RODRIGUES, 2007).

Foram catalogadas cerca de 1.000 edificações inseridas na Zona A (área de maior influência do enchimento do reservatório em função da futura posição do nível de água). Quanto ao potencial colapsível do solo, tais edificações foram classificadas em normais (cerca de 600), razoáveis (cerca de 300) e preocupantes (cerca de 100).

De todas as edificações cadastradas, cerca de 20 delas foram selecionadas para 0 monitoramento dos recalques ao longo da elevação do nível d'água, com a instalação de equipamentos como medidores de nível d'água, medidores de recalques de hastes, 


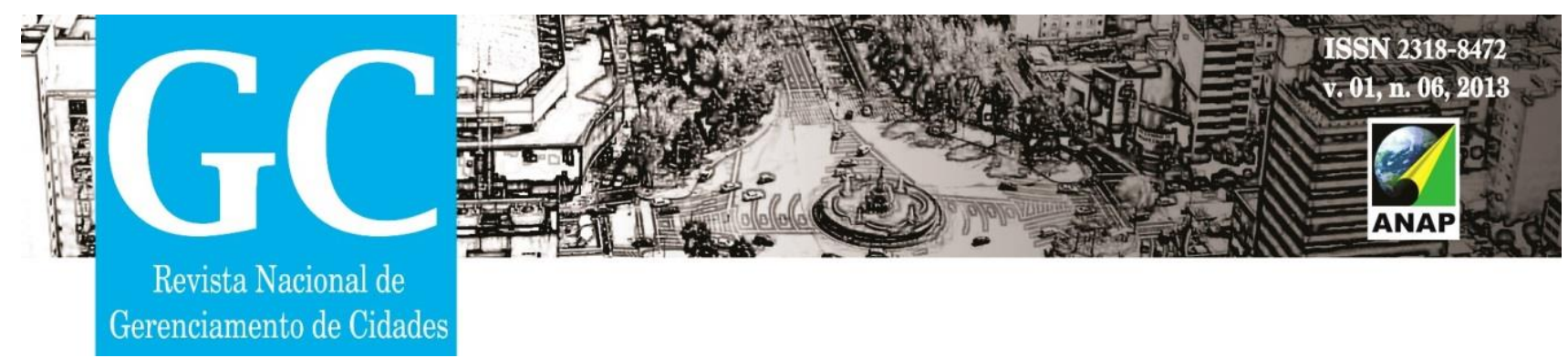

inclinômetros e pinos de nivelamento. $O$ trabalho de monitoramento iniciou-se com a inspeção visual de edificações e abertura de trincheiras, devido à escassez de dados de projeto das construções.

Em dezembro de 1987 foi realizado um cadastramento das construções de maior porte e de maior importância social para a cidade. Em novembro de 1988, foi efetuada uma descrição resumida de cada edificação. Dessa descrição constaram o tipo de fundação e as anomalias estruturais existentes (CESTARI Jr. \& CELERI, 1999).

A posição do nível d'água após o enchimento do lago, os dados cadastrais levantados na cidade e os estudos geotécnicos levaram à consciência de que os impactos provocados pela colapsibilidade do solo não afetariam todas as edificações da área urbana. As construções mais suscetíveis ao colapso estavam, portanto, situadas na borda do futuro lago, onde se previa lençol freático com profundidade de 0 a $5 \mathrm{~m}$, isto é, na Zona $A$.

As leituras de recalque das edificações e de elevação de nível d'água foram iniciadas em janeiro de 1990 e prosseguiram por um período de quase seis anos. A freqüência de leituras variou de duas a três por semana, no início, a trimestral, no final do período, quando se verificou a estabilização do lençol freático (CESTARI Jr. \& CELERI, 1999).

$\mathrm{Na}$ Figura 4 são apresentados recalques e elevação do lençol freático ao longo do tempo de uma das edificações monitoradas. É possível observar nesta figura que os maiores recalques ocorreram durante a subida do lençol freático, o máximo recalque absoluto foi de $119 \mathrm{~mm}$ e o máximo diferencial de $100 \mathrm{~mm}$, o que causou grandes rachaduras sobre os vãos, portas e janelas e também no piso. A edificação, por razões de segurança, foi demolida e reconstruída em seguida no mesmo local.

Outras edificações inseridas na Zona A, a maioria delas construída sem critérios técnicos, apresentaram comportamento semelhante que, ao correlacionar as leituras dos marcos de recalques com as leituras da posição do nível d'água, concluiu-se que os recalques maiores ocorreram no período em que ocorreram as grandes elevações do lençol freático. 

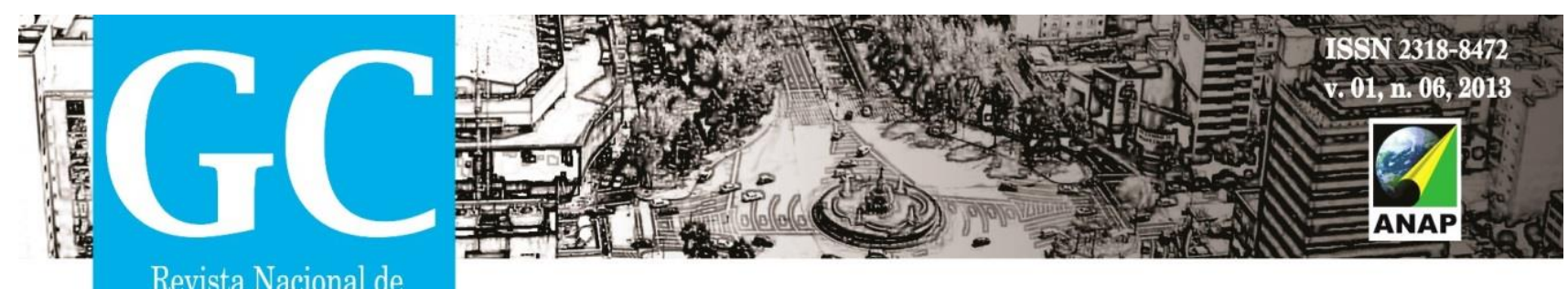

Gerenciamento de Cidades

$\mathrm{Na}$ Figura 5 são apresentadas exemplos de avarias em edificações localizadas às margens do lago de Três Irmãos que sobrevieram durante o enchimento do lago de Três Irmãos e a subseqüente ascensão do lençol freático em Pereira Barreto.

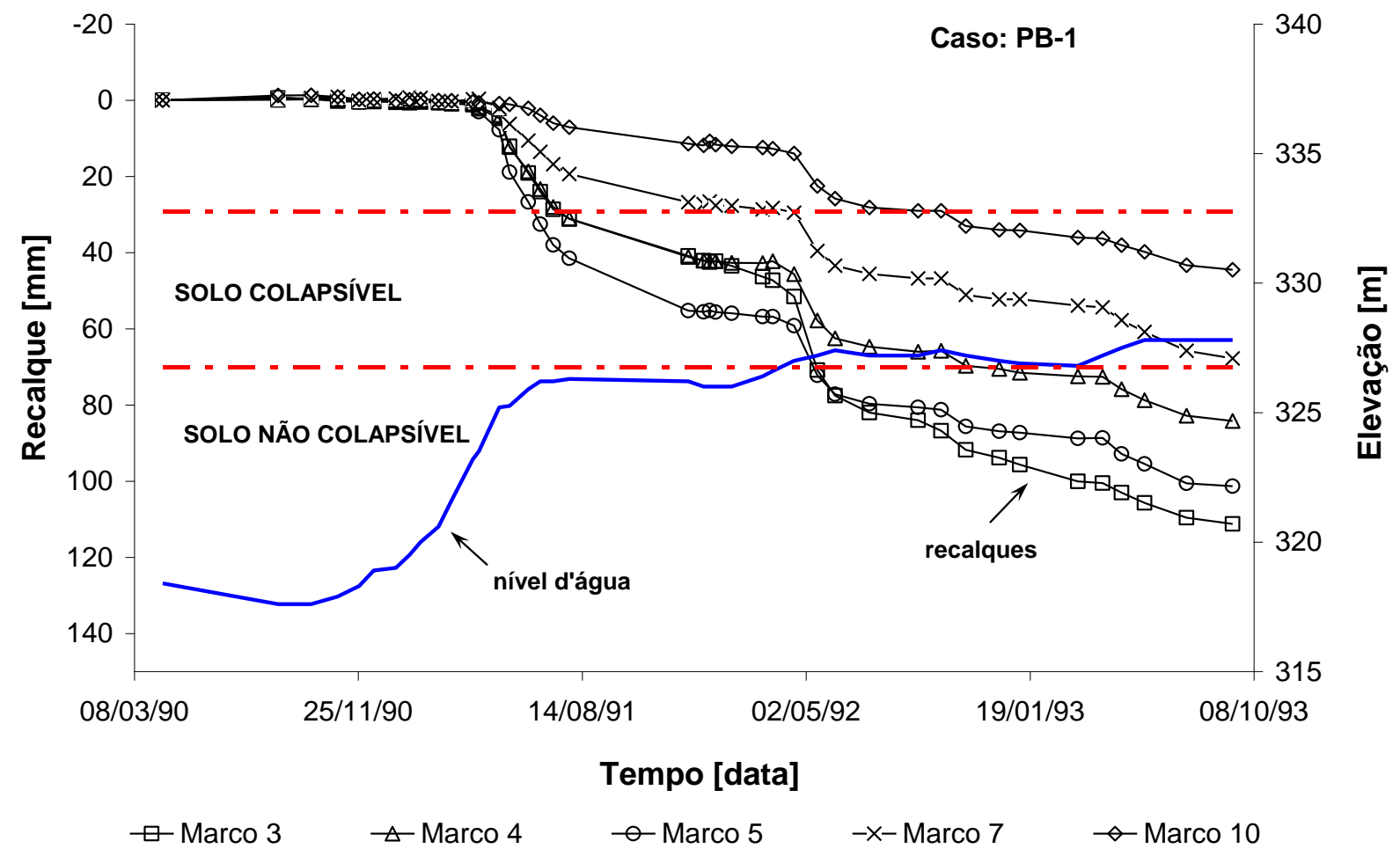

Figura 4. Medidas de recalque e elevação de nível d'água resultantes do monitoramento de uma edificação localizada na Zona A (CESTARI Jr. \& CELERI, 1999; VILAR \& RODRIGUES, 2011). 

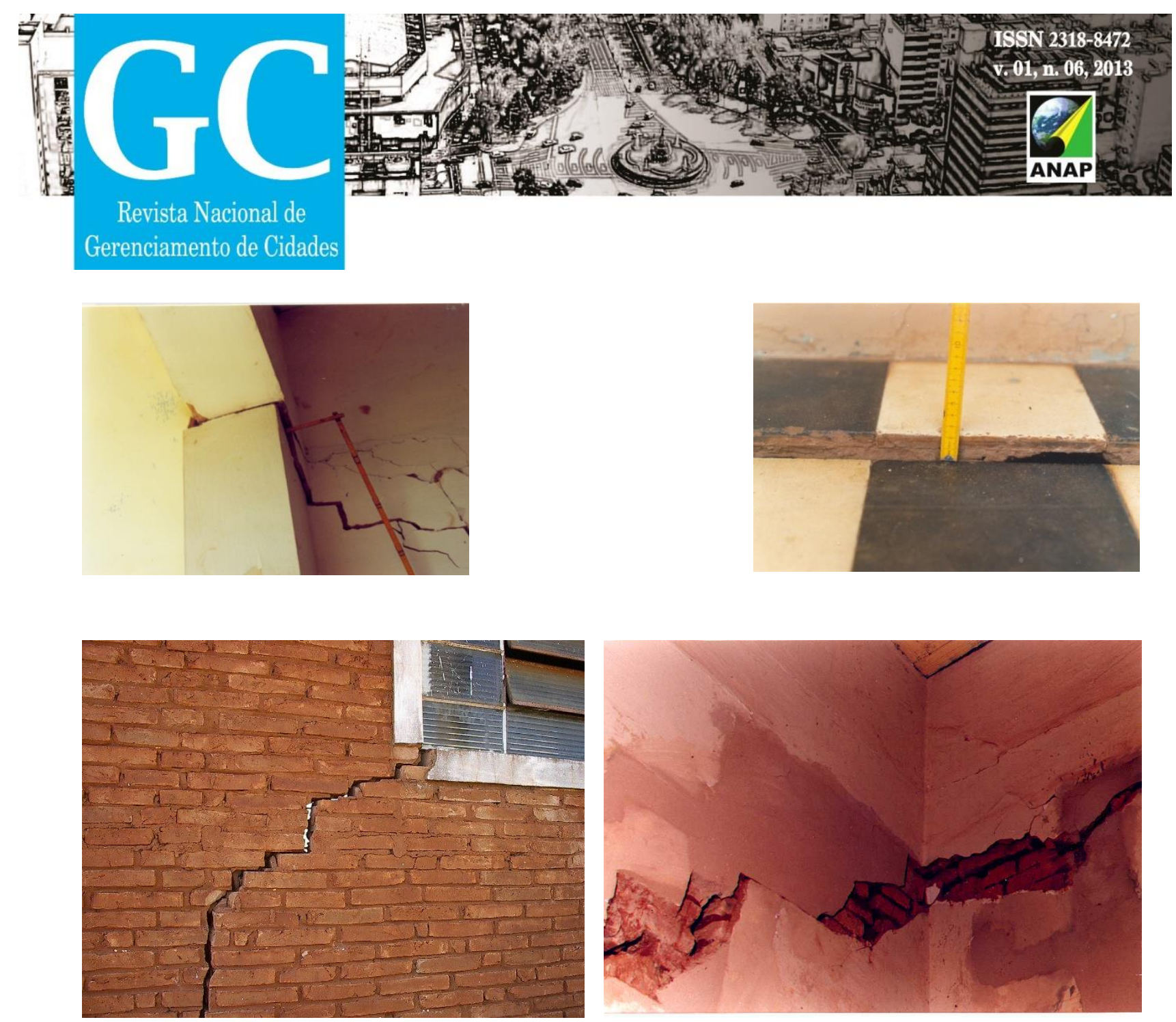

Figura 5. Avarias de construções localizadas na Zona A (RODRIGUES, 2007).

O monitoramento efetuado sistematicamente desde 1987 até o final do ano de 1994, acrescido de algumas medições executadas posteriormente, mostrou elevações no lençol freático de até cerca de 20 metros, induzindo desabamento de paredes de poços-cacimba sem revestimento, recalques no solo e danos a edificações. Tais ocorrências levaram a CESP a adotar uma série de medidas como: reformas, demolição ou reconstrução de cerca de 300 casas; reinstalação de rede de esgoto e estação de tratamento de esgoto; construção de cemitério suspenso (ossário e columbário) na porção mais baixa do cemitério municipal, onde estava previsto lençol freático muito raso; remoção do antigo lixão; perfuração de poço tubular no Aqüífero Guarani, além de outras ações compensatórias como um todo (ALBUQUERQUE FILHO et al., 1987; SANTOS, 2002). 


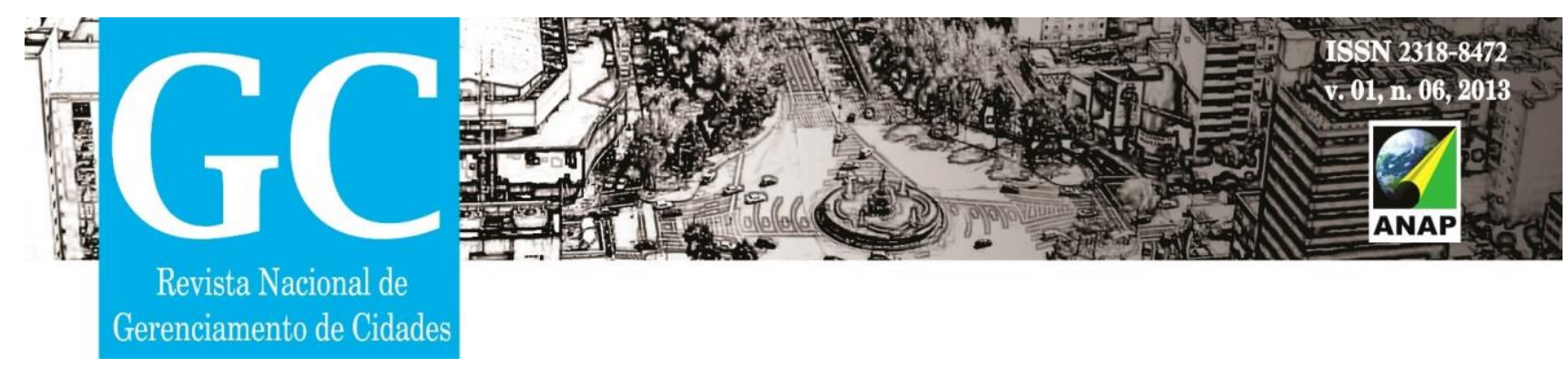

\section{MEDIDAS PARA MINIMIZAR O EFEITO DA COLAPSIBILDIADE DOS SOLOS}

No caso específico de Pereira Barreto, alguns cuidados, tomados na fase de elaboração do projeto de fundações, poderiam reduzir parte dos danos nas edificações atingidas pelo colapso do solo e, deste modo, diminuir os impactos gerados na área urbana do município.

Dos métodos de investigação do subsolo, o ensaio de sondagem à percussão ou sondagem de simples reconhecimento SPT (standard penetration test) e o ensaio de penetração estática ou ensaio de cone CPT (cone penetration test) são os mais comuns para fins de dimensionamento de fundações.

$\mathrm{Na}$ etapa de investigação do subsolo, um aspecto relevante é que a inundação do solo colapsível afeta os resultados de ensaios de penetração, com redução dos valores do índice de resistência à penetração $\left(N_{S P T}\right)$ do SPT e da resistência de ponta $\left(q_{c}\right)$ do CPT.

Em uma campanha de investigação do subsolo em solo colapsível pode-se cogitar como alternativa a realização de ensaios com pré-inundação do terreno em parte dos furos de sondagem da campanha. De acordo com Cintra (2004), no caso do SPT, em particular, é possível que a prática contrária à norma de, na perfuração, usar o sistema com circulação de água antes de atingir o nível d'água, reproduza, de certa forma, a condição de inundação necessária para o colapso.

No tocante aos tipos de fundações, na NBR 6122/96 prescreve-se que, em princípio, devem ser evitadas fundações superficiais apoiadas em solos colapsíveis, a não ser que sejam feitos estudos considerando-se as tensões a serem aplicadas pelas fundações e a possibilidade de encharcamento do solo. Pode-se acrescentar, neste caso, a possibilidade de viabilizar as fundações por sapatas em solos colapsíveis por meio da compactação do solo em cava (SOUZA, et al. 1995; CINTRA, 2004).

Já em projetos de fundações por estacas geralmente existe a opção de escolher 0 tipo e a profundidade de apoio do elemento estrutural de fundação. Em solos colapsíveis 


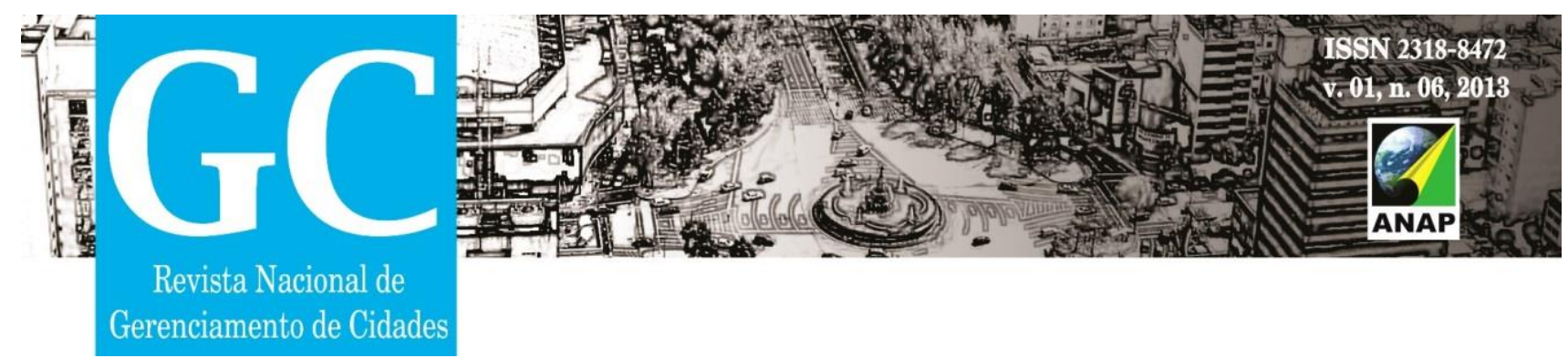

uma forma de minimizar o efeito da colapsibilidade é reduzir a carga admissível de projeto para garantir uma segurança mínima ao colapso.

\section{CONCLUSÃO}

Este trabalho consiste no relato do caso histórico de colapso dos solos registrado na região noroeste do Estado de São Paulo durante e após a construção da UHE de Três Irmãos. Na cidade de Pereira Barreto, o lençol freático sofreu um processo de elevação induzida durante o enchimento do reservatório da usina hidrelétrica. A elevação do nível d'água provocou recalques em fundações de edificações localizadas às margens do lago, levando a responsável pelo empreendimento hidrelétrico a adotar uma série de medidas compensatórias.

Este caso demonstra a necessidade de estudos mais detalhados na etapa de investigação geotécnica, antes da implantação das obras de engenharia. O custo de uma investigação geotécnica para fins de projeto de fundações é relativamente baixo quando comparado ao custo final da obra.

No caso específico de Pereira Barreto alguns dos problemas advindos da elevação induzida do lençol freático poderiam ter sido minimizados, caso medidas tivessem sido tomadas nos projetos de fundações das edificações do município antes da construção da UHE de Três Irmãos.

\section{REFERÊNCIAS}

ABNT. Projeto e execução de fundações. NBR 6122, Rio de Janeiro, 1996. 33 p.

ALBUQUERQUE FILHO, J. L. Previsão e análise da elevação do nível do lençol freático na Avaliação de Impacto Ambiental (AIA) de reservatórios hidrelétricos. 2002. 222 f. Rio Claro. Tese de Doutorado (Doutorado em Geociências) - Universidade Estadual Paulista Júlio de Mesquita Filho, Rio Claro, 2002. 


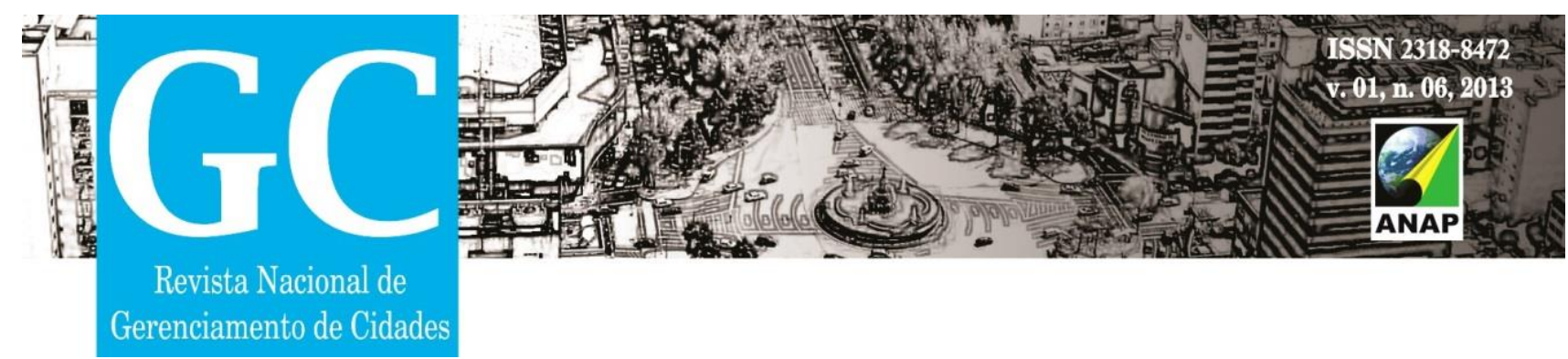

CESTARI JÚNIOR, E; CELERI, A. Reflexos do enchimento do reservatório da UHE Três Irmãos nas edificações da cidade de Pereira Barreto. In: SEMINÁRIO NACIONAL DE GRANDES BARRAGENS, 23., 1999, Belo Horizonte. Anais...Belo Horizonte: CBDB, 1999. p. 79-86.

CLEMENCE, S. P; FINBARR, A. O. Design Considerations for Collapsible Soils. Journal of the Geotechnical Engineering Division, ASCE, v. 107, n. 3, p. 305-317, march. 1981.

CINTRA, J. C. A. Aplicações da mecânica dos solos não saturados - fundações em solos colapsíveis. In: SIMPÓSIO BRASILEIRO DE SOLOS NÃO SATURADOS, 5., 2004, São Carlos. Anais...São Carlos: USP, 2004. p. 575-594.

DUDLEY, J. H. Review of Collapsing Soils. Journal of the Soil Mechanics and Foundation Division, v. 96, n. 3, p. 925-947, 1970.

NUÑES, E. Suelos especiales: colapsables, expansivos, preconsolidados por desecación. In: CONGRESO PANAMERICANO DE MECANICA DE SUELOS E INGINIERÍA DE FUNDACIONES, 5, Buenos Aires, Proceedings...Buenos Aires: 4., Sessão II, 1975. 43-73 p.

RODRIGUES, R. A. Modelação das deformações por colapso devidas à ascensão de lençol freático. 2007. 262 f. Tese de Doutorado (Doutorado em Geotecnia) - Escola de Engenharia de São Carlos da Universidade de São Paulo, São Carlos, 2007.

SANTOS, A. R. Geologia de Engenharia: conceitos, método e prática. São Paulo: ABGE (Publicação IPT 2797). 2002. 222p.

SOUZA, A.; CINTRA, J. C. A.; VILAR, O. M. Shallow Foundations on Collapsible Soil Improved by Compaction. In: INTERNATIONAL CONFERENCE ON UNSATURATED SOILS (UNSAT 95), 1., 1995, Paris, Proceedings..., Paris. 1995. p. 1017-1021. 


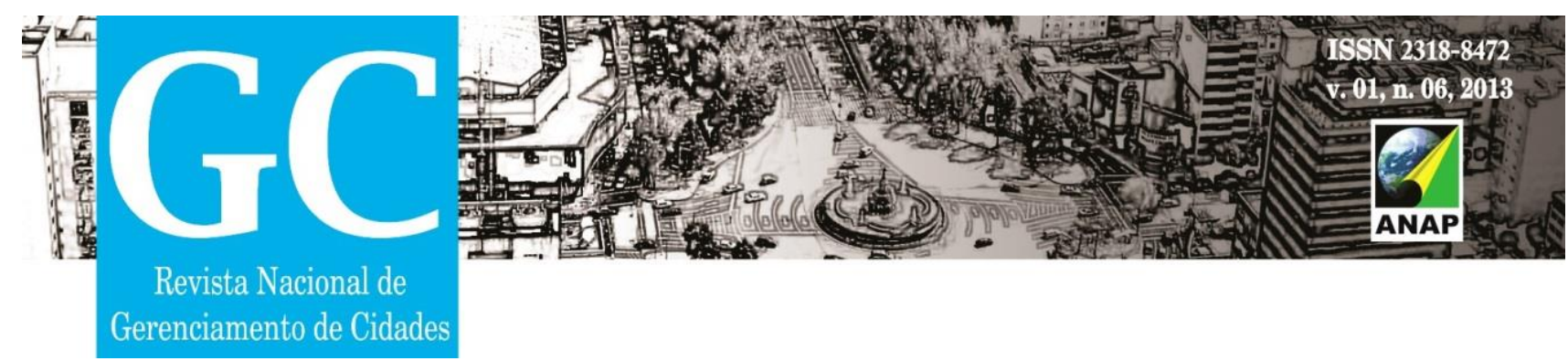

VILAR, O. M.; RODRIGUES, J. E.; NOGUEIRA, J. B. Solos Colapsíveis: um problema para a engenharia de solos tropicais. In: SIMPÓSIO BRASILEIRO DE SOLOS TROPICAIS EM ENGENHARIA, 1.,1981, Rio de Janeiro, Anais..., Rio de Janeiro. 1981. p. 209-224.

VILAR, O. M.; GAIOTO, N. Comportamento colapsível de um solo laterítico compactado. In: SIMPÓSIO BRASILEIRO DE SOLOS NÃO SATURADOS, 2., 1994, Recife, Anais..., Recife, 1994. $185-190 \mathrm{p}$.

VILAR, O. M; RODRIGUES, R. A. Collapsible behavior of soil in a Brazilian region affected by a rising water table. Canadian Geotechnical Journal, v. 48, n. 2, p. 226-233, 2011. 